\title{
Preclinical carotid atherosclerosis as an indicator of polyvascular disease: a narrative review
}

\author{
Pavel Poredos $^{1,2}$, Mateja K. Jezovnik ${ }^{2} \wedge$ \\ ${ }^{1}$ Department of Vascular Disease, University Medical Centre Ljubljana, Ljubljana, Slovenia; ${ }^{2}$ Department of Advanced Cardiopulmonary Therapies \\ and Transplantation, The University of Texas Health Science Centre at Houston, Houston, TX, USA \\ Contributions: (I) Conception and design: Both authors; (II) Administrative support: MK Jezovnik; (III) Provision of study materials or patients: Both \\ authors; (IV) Collection and assembly of data: P Poredos; (V) Data analysis and interpretation: P Poredos, MK Jezovnik; (VI) Manuscript writing: \\ Both authors; (VII) Final approval of manuscript: Both authors. \\ Correspondence to: Pavel Poredos, MD, PhD. Department of Vascular Disease, University Medical Centre Ljubljana, Zaloska 7, SI-1000 Ljubljana, \\ Slovenia. Email: pavel.poredos@kclj.si.
}

\begin{abstract}
Carotid atherosclerotic lesions are correlated with atherosclerotic deterioration of the arterial wall in other vascular territories and with cardiovascular events. The detection of pre-symptomatic carotid lesions like intima-media thickness (IMT) and asymptomatic carotid plaques is possible by non-invasive ultrasound duplex scanning. Current measurement guidelines suggest an average measurement of IMT within $10 \mathrm{~mm}$ of the segment of the common carotid artery. The thickening of intima-media appears in a long subclinical period of atherosclerosis. Therefore, the determination of IMT has emerged as one of the methods for determining early structural deterioration of the arterial wall. A close interrelationship was shown between IMT and risk factors of atherosclerosis, their duration, and intensity. Different studies demonstrated that increased IMT is a powerful predictor of coronary, cerebrovascular, and peripheral arterial occlusive disease and their complication. A recent meta-analysis indicated a minimal improvement in the risk estimation of cardiovascular events after adding IMT to the Framingham Risk Score. These findings influenced the latest ACC/AHA guidelines which again recommend the use of carotid IMT measurement for individual risk assessment. The presence of atherosclerotic plaques indicates that the atherosclerotic process is already ongoing. The findings of different studies are equivocal that carotid plaques independently predict cardiovascular events and improve risk predictions for coronary artery disease when added to the Framingham Risk Score. However, besides the size of plaque and grade of stenosis, the structure of plaque calcification, vascularization, lipid core, and the surface of plaques are important indicators of related risks for cardiovascular events.
\end{abstract}

Keywords: Atherosclerosis; carotid ultrasound; intima-media thickness; cardiovascular disease risk factors; carotid plaque

Submitted Jul 29, 2020. Accepted for publication Jun 29, 2021.

doi: 10.21037/atm-20-5570

View this article at: https://dx.doi.org/10.21037/atm-20-5570

\section{Introduction}

Carotid atherosclerosis represents one of the most frequent manifestations of vascular disease. Carotid atherosclerotic lesions are not only an indicator of local deterioration of the vessel wall but also indicate systemic atherosclerotic disease, often with concomitant lesions in coronary and peripheral vascular beds (1). In patients with significant carotid stenosis, coronary artery disease $(\mathrm{CAD})$ was found in $68 \%$, while renal artery stenosis and peripheral artery occlusive disease (PAD) were found in $20 \%$ and $21 \%$ of patients,

\footnotetext{
^ ORCID: Pavel Poredos, 0000-0002-9913-1419; Mateja Kaja Jezovnik, 0000-0002-5317-0148.
} 
respectively (2).

Paraskevas and coworkers showed that $70 \%$ of patients with internal carotid artery (ICA) occlusion had atherosclerotic disease in at least 1 additional vascular territory (3). It was also shown that severe (but not moderate) carotid atherosclerosis may predict concomitant vascular disease in other arterial territories (4). In contrast, Adraktas et al. failed to find an interrelationship between carotid atherosclerosis and coronary, vertebral, or aortic atherosclerosis in patients with acute stroke symptoms (5). They concluded that despite atherosclerosis being a diffuse process; it is significant in one type of artery at a time and that propensity of atherosclerosis is to be severe in one vascular bed while not in others. The reason Adraktas et al. failed to find a relationship between carotid and coronary atherosclerosis could be the consequence of inclusion criteria used in their study, which also included the moderate degree of carotid stenosis $(>50 \%)$.

Carotid atherosclerotic disease is also significantly related to PAD and it was shown that there is a relationship between the severity of PAD and carotid occlusive disease (6). Further, the presence and severity of PAD were shown to be associated with the prevalence of carotid atherosclerosis regardless of lower extremity symptoms (7).

The easy accessibility of carotid arteries for noninvasive investigation represents a "window" to the whole circulatory system. As atherosclerosis is a systemic disease, characterization of carotid arteries represents a useful tool for the prediction of atherosclerosis in other territories, particularly of coronary arteries, and enables estimation of total atherosclerotic burden (8).

Subclinical atherosclerotic lesions of carotid arteries are accessible by non-invasive imaging modalities like ultrasound and magnetic resonance imaging. The presence of atherosclerotic plaques, their structure, and intimamedia thickness (IMT) of carotid arteries are indicators of atherosclerosis in other vascular territories and might help identify patients at risk for myocardial infarction or stroke.

We present the following article in accordance with the Narrative Review reporting checklist (available at https:// dx.doi.org/10.21037/atm-20-5570).

\section{Data sources and searches}

Relevant articles evaluating the association of preclinical carotid artery disease with atherosclerotic processes in other vascular beds were identified through a comprehensive search of Ovid MEDLINE, Ovid Embase, and the
Cochrane Library performed by both authors the last time on May 20th, 2020. Additional articles were identified through a search of the references and citing articles of each selected article using the "View References" and "Cited by" tools in Scopus. No language restriction was applied.

\section{Increased intima-media thickness (IMT)-an indicator of early carotid atherosclerosis}

Cardiovascular atherosclerotic lesions become clinically significant in a stage of a well-advanced atherosclerotic process. However, vessel wall changes occur during the long subclinical lag phase characterized by endothelial dysfunction and gradual thickening of intima-media (9). Determination of IMT of large superficial arteries, especially the carotid, using B-mode ultrasonography has emerged as one of the methods of choice for determining early structural deterioration of arterial wall and assessing cardiovascular risk (10). IMT measurements obtained by ultrasonography are well reproducible and represent a precise indicator of pathophysiologic characteristics of the arterial wall (11). IMT acts as a cost-effective surrogate endpoint of cardiovascular disease and stroke in a situation when the accurate cardiovascular and stroke endpoints would need longitudinal trials (12). It is also an additional useful tool for estimation of risk for cardiovascular events.

\section{Methods of IMT measurement}

There exist different ultrasound protocols for the measurement of carotid IMT. They differ in the involvement of the number of segments of carotid arteries (common carotid artery, bifurcation, ICA), types of measurement (manual or automatic IMT detection), and values of IMT (average IMT, maximal IMT) (13). This may concern scanning procedures concerning the segments and direction of the wall of measurement. There are also differences in IMT image analysis with respect to the type of measure (mean maximum, mean random) and determination of the echo boundary defining the IMT interface which may be manual or automated computerized edge identification (9). Recently, the common carotid artery (CCA) is being examined more frequently than the ICA and the bifurcation. In the current measurement guidelines, the average measurement of IMT has been proposed within a $10 \mathrm{~mm}$ segment of the CCA (14). Good quality scans of CCA with the best reproducibility can be achieved in most patients, in contrast with those of the ICA and the carotid bifurcation (15). The ICA is difficult 
to visualize. Therefore, the measurements of ICA IMT are often missing and have large intra- in interobserver variability.

Another important point represents the measurement of CCA-IMT. There are different types of CCA-IMT measurements, such as the mean of CCA-IMT values along the $10 \mathrm{~mm}$ segment of CCA, maximum IMT values of the $10 \mathrm{~mm}$ distal CCA, mean of mean measurements in which left and right CCA is measured, and the average of mean CCA-IMT values of both sides. Another approach suggests measurements of IMT in three segments of extracranial carotid arteries (CCA, bifurcation, ICA) on both sides of the artery wall (16). For each segment, the maximum value of IMT is selected and the final IMT is the average of IMT values at the 12 -sides of the examination.

Most investigators determine the IMT of the far wall only, whereas others combine its measurement with that of the near wall $(17,18)$. When only the near-wall IMT is visualized, its measurement is gain-dependent and therefore subject to greater variability (19).

Ultrasound scanning of the arterial segment can be performed in one or more directions (anterolateral, lateral, postero-lateral). Measuring in more directions will give more realistic results, particularly in the case of wallthickness eccentricity (20).

The reproducibility of IMT measurement is dependent on the site of measurement and the method of reading. Intra-observer variability in selected studies ranged from a mean SD difference of $0.02 \pm 0.02$ to $0.66 \pm 1.13 \mathrm{~mm}$ and a variation coefficient from $2.4 \%$ to $10.6 \%$ (17). Reproducibility of IMT measurement is worse in studies that include measurement of ICA and bifurcation than in studies limited to the CCA. Intra- and interobserver variability was better in studies using the automated edge-tracking method than when the leading edges were determined by visual assessment (18).

\section{The association between cardiovascular risk factors and IMT}

A close relationship between IMT with many cardiovascular risk factors has been reported $(9,21)$. Carotid IMT increased significantly with age, by $0.04 \mathrm{~mm}$ for every 10 years (22). Further, carotid IMT is affected by lifestyle. In the Monitored Atherosclerosis Regression Study (MARS) cholesterol intake, body mass index (BMI), and smoking were significantly related to the annual progression of the carotid IMT (23). It was also shown that the increase in carotid IMT is related to the duration and number of cigarettes smoked $(24,25)$. Not only active but environmental tobacco smoke exposure was associated with increased carotid IMT and males were more affected (26). A close relationship of IMT to impaired glucose tolerance was shown with type 2 diabetes (27). The concentration of glycated hemoglobin and the duration of type 2 diabetes were independent predictors of the thickening of carotid intima-media (28).

Of all traditional risk factors, hypertension appears to have the greatest effect on IMT $(29,30)$. The Plaque Hypertension Lipid-Lowering Italian Study (PHYLLIS) showed that systolic and pulse pressure together with age are the most significant factors associated with increased carotid IMT in hypertensive patients (29). One of our studies showed that normotensive children of parents with essential hypertension have increased IMT, which suggests that genes and not the level of blood pressure influence IMT (31).

\section{Carotid IMT and cardiovascular events}

In the last decades, IMT has been considered as a non-invasive quantitative tool for the assessment of cardiovascular and stroke risk $(10,32)$. Carotid IMT has also been an established measure for assessing the extension of atherosclerosis (33), and it is associated with cardiovascular alteration (34). Bots and coworkers found an association between increased carotid IMT and atherosclerosis of lower limb arteries as assessed by ankle-brachial index (ABI) $(22,27,35)$. In the Atherosclerosis Risk in Communities (ARIC) study, the correlation between an increased carotid IMT and prevalent clinical cardiovascular disease was most expressed in subjects with intermittent claudication (36). Different studies demonstrating that increased IMT is a powerful predictor of coronary and cerebrovascular events, whatever the method and the site of IMT measurement (37-39). The Kuopio Ischemic Heart Disease Study showed an $11 \%$ increased risk of myocardial infarction in each $0.1 \mathrm{~mm}$ incremental increase of carotid IMT (40). Also, several large studies like Atherosclerosis Risk in Communities Study (ARIC) (41), the Cardiovascular Health Study (42), and The Carotid Atherosclerosis Progression Study (43) showed the same results. The study of Polak showed that mean IMT in the CCA and maximum IMT of the ICA were significantly associated with the risk of cardiovascular disease (44). Carotid IMT and carotid plaques predicted cardiovascular and renal outcomes and improved renal risk stratification in patients with type 
2 diabetes (45). In the study of Lorenz et al., it was shown that common IMT is associated with future CAD events risk; however, this was not true for its change over time. Therefore, changes of IMT should be interpreted with care (46). A meta-analysis that included 20 studies with 35 to 500 patients showed that carotid IMT may serve as an accurate diagnostic tool. A cut-off value of $1 \mathrm{~mm}$ seems to provide an accurate risk assessment of CAD (sensitivity: 0.66, specificity 0.79 ; AUC 0.80 ) (38).

However, it is not clear whether IMT significantly contributes to the Framingham Risk Factors for cardiovascular risk prediction. In one study, the addition of IMT slightly increased predictive power concerning cardiovascular risk assessment (47) and stroke in another study (48). Some other studies showed that IMT determination has little or no additional prognostic value in addition to traditional risk factor scores such as Framingham Risk Score $(49,50)$. Despite these contradictory results in 2010, the American College of Cardiology supported the use of carotid IMT for cardiovascular and stroke risk assessment (class II a recommendation). Similarly, the National Cholesterol Education Programme Adults Treatment Panel (51) and The European Society of Hypertension recommended the use of IMT for cardiovascular and stroke risk prediction (52). However, Den Ruijter at all published a meta-analysis with 11 years of follow-up of IMT measurements (53). IMT was measured within the $10 \mathrm{~mm}$ distance of the far wall of the CCA without plaques. This meta-analysis indicated minimal improvement of risk estimation of cardiovascular events after adding IMT to the Framingham risk score (54). Those findings influenced ACC/AHA guidelines that advised against the use of carotid IMT measurement for individual routine risk assessment (55). Analysis of methods for IMT measurement showed that inconsistency in the measurement of preclinical atherosclerotic lesions influenced the validity of the prediction of cardiovascular events based on IMT measurement (56).

This varying and contradictory results and guideline recommendations are probably caused by differences in study design, special differences regarding carotid IMT measurements, such as measuring CCA, ICA, or both carotid arteries. Results are also influenced by the inclusion or exclusion of atherosclerotic plaques (57). Other important factors influencing carotid IMT are age, sex, and race. To overcome this problem Polak et al. prepared age, sex, and race ethnic-specific normative values for carotid IMT (58). This approach significantly increases the prediction of cardiovascular events beyond traditional risk factors, even when coronary artery calcium was included in the model. Improving the accuracy of risk prediction is very important because it helps target those subjects who are most likely to benefit from preventive treatment.

\section{Carotid plaques}

Atherosclerotic plaques represent a recognizable and frequently advanced form of atherosclerosis. Their presence indicates that the atherosclerotic process is going on. As atherosclerosis is a systemic disease, it is expected that patients with carotid atherosclerotic plaques will have similar lesions also in other territories of arterial circulation. According to the definition, carotid plaques represent focal arterial wall thickening of $50 \%$ greater than surrounding IMT of the vessel wall or a focal region with IMT greater than $1.5 \mathrm{~mm}$ protruding into the lumen (59). Touboul et al. added a measure for the carotid plaque measurement and defined the plaque as a focal thickening region protruding into the lumen by at least $0.5 \mathrm{~mm}$ or $50 \%$ of the surrounding IMT values or an absolute value of IMT greater than $1.5 \mathrm{~mm}$ (14).

The structure of plaques is beside their size an important indicator of risk for cardiovascular events. Vulnerable plaques are unstable and tend to rupture easily (60). Nonstable plaques have specific structural characteristics which include a large lipid core, thin fibrous cap with inflammatory cell infiltration, and intra-plaque hemorrhage (61).

\section{Carotid plaques and cardiovascular events}

The presence of carotid plaques independently predicts cardiovascular events and improves risk stratification for coronary heart disease when added to the Framingham Risk Factors (62).

Different studies showed that the carotid plaque presence is a better predictor of cardiovascular disease than carotid IMT (63). Recent studies suggest that the quantitative carotid plaque scores, like number, thickness, surface, area, and texture of plaques characterized by $2 \mathrm{D}$ ultrasound may be the best predictors of CVD risk (64). Recently, 3D ultrasound has been used for a more accurate assessment of plaque volume. Patients with familial hypercholesterolemia who have carotid plaques have 4.34 times higher relative risk of cardiovascular events and the number of carotid artery plaques was positively associated with the risk of cardiovascular events (65). In the study of Shah, the 
presence of carotid plaque predicted any coronary plaque on computed tomography angiography (CTA) with an odds ratio of 2.8 and the presence of any calcified coronary plaque with an odds ratio of 5.4 (66). An association was found also between carotid atherosclerosis and peripheral artery disease (PAD). Both, symptomatic and asymptomatic PAD was associated with greater odds of carotid artery stenosis. The increasing severity of PAD was associated also with a greater risk of coronary atherosclerosis (7).

The structure of plaques is an important determinant of cardiovascular risk and it was shown that the composition of carotid plaque is related to the structure of coronary plaque $(20,67)$. The study of Hellings et al. showed a relationship between carotid plaque composition and future cardiovascular events. Specimens of carotid atherosclerotic lesions were collected from patients who underwent carotid endarterectomy and were subject to histological examination. In the follow-up period up to 3 years, 196 of 818 patients $(24 \%)$ reached the primary outcome (vascular death, nonfatal stroke, nonfatal myocardial infarction) (68). Patients whose carotid specimens revealed plaque hemorrhage or intra-plaque vessel formation demonstrated an increased risk for the primary outcome. However, macrophage infiltration, size of lipid core, and calcification were not associated with clinical outcomes. Another study showed that in middle-aged adults free of cardiovascular disease total carotid plaque area but not greyscale plaque features were associated with cardiovascular risk factors and predicted incidental coronary events (69). In the Multi-Ethnic Study of Atherosclerosis (MESA) magnetic resonance imaging (MRI) and ultrasound characteristics of carotid plaques of 946 participants who were at or above the 85 th percentile according to carotid IMT were followed for 5.5 years and cardiovascular events were registered (70). The identification of vulnerable plaque with MRI was a useful tool for cardiovascular disease prediction and significantly improved the reclassification of baseline cardiovascular risk. Carotid artery remodeling and the size of the lipid core were independent predictors of new cardiovascular events. Therefore, carotid artery imaging provides a useful surrogate marker of generalized vascular health and identifies "vulnerable patients" at risk for subsequent cardiovascular events.

\section{Carotid intima-media thickness versus carotid plaque burden for predicting cardiovascular risk}

The measurement of IMT was in recent decades used for the prediction of cardiovascular events. However, different studies and a meta-analysis of population-based studies showed that carotid plaques compared to IMT had a significantly higher diagnostic accuracy for the prediction of future coronary events. A meta-analysis of Inaba et al. showed that the ultrasound assessment of carotid plaque compared to that of IMT had a higher diagnostic accuracy for the prediction of future cardiovascular events (64). Further, one of the most important studies of the relationship between carotid plaques and cardiovascular events was the TROMSØ Norway study, which showed that measurement of plaque burden is more strongly predictive of cardiovascular events compared to the measurement of IMT (71). While the addition of IMT to plaque presence failed to improve the arterial event in older patients, IMT improved the ability to detect stroke and critical ischemia when added to the plaque in younger patients (72). It was concluded that IMT complements the poor performance of carotid plaque presence for cardiovascular event detection in younger but not in older patients. However, it is important to take into account that IMT is biologically and genetically distinct from the plaque burden (73). Determination of plaque burden, which includes plaque thickness and total plaque area was shown to be related to increased risk for $\mathrm{CV}$ events. Further, carotid plaque burden is as predictive as coronary calcium score for future CV events (74), and plaque burden was more predictive of $\mathrm{CV}$ events compared to the measurement of IMT (64). The predictive value of preclinical atherosclerotic lesions depends also on the location of these lesions. In the Tromsø Study., total plaque area strongly predicted coronary risk after 6 years of followup, whereas only IMT in the bulb was predictive (75). The High-Risk Plaque BioImage Study compared IMT carotid plaque burden and maximum plaque thickness. Both carotid plaque burden and carotid plaque thickness were predictive of primary and secondary major CV events, whereas IMT was not (76). A major advantage of measuring carotid plaque burden is that progression or regression of plaques can be measured precisely and their changes appear in short time frames. Plaque volume and area change within 3 months, so they are effective measures to assess the effect of preventive treatment (77). The interrelationship between carotid IMT, carotid plaque burden and cardiovascular events is shown in Table 1.

In conclusion, detection of preclinical atherosclerotic lesions in carotid arteries has been considered as a noninvasive quantitative tool for the assessment of cardiovascular and stroke risks. The determination of plaque burden is 
Table 1 Inter-relationship between IMT and cardiovascular incidents

\begin{tabular}{|c|c|c|}
\hline Study & Study population & Findings \\
\hline CHS (78) & 4,476 older adults & IMT $=1.18$ is associated with a fourfold greater risk for AMI and stroke over 6 years \\
\hline CLAS (79) & $\begin{array}{l}162 \text { men with coronary } \\
\text { bypass surgery }\end{array}$ & $\begin{array}{l}\text { Each increase in IMT of } 0.03 \mathrm{~mm} \text { per year is related to a relative risk of } 3.1 \mathrm{for} \\
\text { cardiovascular events }\end{array}$ \\
\hline $\begin{array}{l}\text { The Rotterdam } \\
\text { Study (80) }\end{array}$ & 1,870 elderly subjects & $\begin{array}{l}0.16 \mathrm{~mm} \text { increase in IMT is accompanied by a risk ratio of } 1.4 \text { for } \mathrm{AMI} \text { or stroke over } \\
3 \text { years }\end{array}$ \\
\hline $\begin{array}{l}\text { The Framingham } \\
\text { Offspring study (44) }\end{array}$ & 2,965 subjects & The hazard ratio for CVD was 1.13 for CCA and 1.21 for ICA \\
\hline
\end{tabular}

ARIC, Atherosclerosis Risk in Communities; KIHD, Kuopio Ischemic Heart Disease Study; CHS, The Cardiovascular health Study; CLAS, Cholesterol Lowering Atherosclerosis Study; CVD, cardiovascular disease; AMI, acute myocardial infarction; CVD, cardiovascular disease; IMT, intima-media thickness; CAD, coronary artery disease; CCA, common carotid artery; ICA, internal carotid artery.

more strongly predictive of cardiovascular events compared to the measurement of IMT. Determination of risk is more predictive if the measurement of IMT is combined with the determination of plaque thickness and total plaque area.

\section{Acknowledgments}

Funding: None.

\section{Footnote}

Provenance and Peer Review: This article was commissioned by the Guest Editor (Kosmas I. Paraskevas) for the series "Carotid Artery Stenosis and Stroke - Prevention and Treatment Part II" published in Annals of Translational Medicine. The article has undergone external peer review.

Reporting Checklist: The authors have completed the Narrative Review reporting checklist. Available at https:// dx.doi.org/10.21037/atm-20-5570

Conflicts of Interest: Both authors have completed the ICMJE uniform disclosure form (available at https://dx.doi. org/10.21037/atm-20-5570). The series "Carotid Artery Stenosis and Stroke - Prevention and Treatment Part II" was commissioned by the editorial office without any funding or sponsorship. The authors have no other conflicts of interest to declare.
Ethical Statement: The authors are accountable for all aspects of the work in ensuring that questions related to the accuracy or integrity of any part of the work are appropriately investigated and resolved.

Open Access Statement: This is an Open Access article distributed in accordance with the Creative Commons Attribution-NonCommercial-NoDerivs 4.0 International License (CC BY-NC-ND 4.0), which permits the noncommercial replication and distribution of the article with the strict proviso that no changes or edits are made and the original work is properly cited (including links to both the formal publication through the relevant DOI and the license). See: https://creativecommons.org/licenses/by-nc-nd/4.0/.

\section{References}

1. Poredos P, Jug B. The prevalence of peripheral arterial disease in high risk subjects and coronary or cerebrovascular patients. Angiology 2007;58:309-15.

2. Wu YW, Lin MS, Lin YH, et al. Prevalence of concomitant atherosclerotic arterial diseases in patients with significant cervical carotid artery stenosis in Taiwan. Int J Cardiovasc Imaging 2007;23:433-9.

3. Paraskevas KI, Mikhailidis DP, Liapis CD. Internal carotid artery occlusion: association with atherosclerotic disease in other arterial beds and vascular risk factors. Angiology 2007;58:329-35. 
4. Paraskevas KI, Mikhailidis DP, Liapis CD. Severe, but not moderate, carotid atherosclerosis may predict concomitant vascular disease in other arterial beds. Stroke 2010;41:e597; author reply e598.

5. Adraktas DD, Brasic N, Furtado AD, et al. Carotid atherosclerosis does not predict coronary, vertebral, or aortic atherosclerosis in patients with acute stroke symptoms. Stroke 2010;41:1604-9.

6. Long TH, Criqui MH, Vasilevskis EE, et al. The correlation between the severity of peripheral arterial disease and carotid occlusive disease. Vasc Med 1999;4:135-42.

7. Razzouk L, Rockman CB, Patel MR, et al. Co-existence of vascular disease in different arterial beds: Peripheral artery disease and carotid artery stenosis--Data from Life Line Screening(®). Atherosclerosis 2015;241:687-91.

8. Ibrahimi P, Jashari F, Nicoll R, et al. Coronary and carotid atherosclerosis: how useful is the imaging? Atherosclerosis 2013;231:323-33.

9. Poredos P. Intima-media thickness: indicator of cardiovascular risk and measure of the extent of atherosclerosis. Vasc Med 2004;9:46-54.

10. O'Leary DH, Bots ML. Imaging of atherosclerosis: carotid intima-media thickness. Eur Heart J 2010;31:1682-9.

11. Riley WA, Barnes RW, Applegate WB, et al. Reproducibility of noninvasive ultrasonic measurement of carotid atherosclerosis. The Asymptomatic Carotid Artery Plaque Study. Stroke 1992;23:1062-8.

12. Bots ML, Evans GW, Tegeler CH, et al. Carotid Intima-media Thickness Measurements: Relations with Atherosclerosis, Risk of Cardiovascular Disease and Application in Randomized Controlled Trials. Chin Med J (Engl) 2016;129:215-26.

13. Saba L, Meiburger KM, Molinari F, et al. Carotid IMT variability (IMTV) and its validation in symptomatic versus asymptomatic Italian population: can this be a useful index for studying symptomaticity? Echocardiography 2012;29:1111-9.

14. Touboul PJ, Hennerici MG, Meairs S, et al. Mannheim carotid intima-media thickness and plaque consensus (2004-2006-2011). An update on behalf of the advisory board of the $3 \mathrm{rd}$, 4th and 5 th watching the risk symposia, at the 13 th, 15 th and 20th European Stroke Conferences, Mannheim, Germany, 2004, Brussels, Belgium, 2006, and Hamburg, Germany, 2011. Cerebrovasc Dis 2012;34:290-6.

15. Wikstrand J, Wendelhag I. Methodological considerations of ultrasound investigation of intima-media thickness and lumen diameter. J Intern Med 1994;236:555-9.

16. Efremov L, Yang WY, Jacobs L, et al. Post-processing reproducibility of the structural characteristics of the common carotid artery in a Flemish population. Artery Res 2017;19:9-17.

17. Pauciullo P, Iannuzzi A, Sartorio R, et al. Increased intima-media thickness of the common carotid artery in hypercholesterolemic children. Arterioscler Thromb 1994;14:1075-9.

18. Blankenhorn DH, Selzer RH, Crawford DW, et al. Beneficial effects of colestipol-niacin therapy on the common carotid artery. Two- and four-year reduction of intima-media thickness measured by ultrasound. Circulation 1993;88:20-8.

19. Linhart A, Gariépy J, Massonneau M, et al. Carotid intima-media thickness: The ultimate surrogate end-point of cardiovascular involvement in atherosclerosis. Applied Radiology 2000;29:25-39.

20. Baldassarre D, Werba JP, Tremoli E, et al. Common carotid intima-media thickness measurement. A method to improve accuracy and precision. Stroke 1994;25:1588-92.

21. Salonen R, Tervahauta M, Salonen JT, et al. Ultrasonographic manifestations of common carotid atherosclerosis in elderly eastern Finnish men. Prevalence and associations with cardiovascular diseases and risk factors. Arterioscler Thromb 1994;14:1631-40.

22. Allan PL, Mowbray PI, Lee AJ, et al. Relationship between carotid intima-media thickness and symptomatic and asymptomatic peripheral arterial disease. The Edinburgh Artery Study. Stroke 1997;28:348-53.

23. Markus RA, Mack WJ, Azen SP, et al. Influence of lifestyle modification on atherosclerotic progression determined by ultrasonographic change in the common carotid intimamedia thickness. Am J Clin Nutr 1997;65:1000-4.

24. Poredos P, Orehek M, Tratnik E. Smoking is associated with dose-related increase of intima-media thickness and endothelial dysfunction. Angiology 1999;50:201-8.

25. Hansen K, Östling G, Persson M, et al. The effect of smoking on carotid intima-media thickness progression rate and rate of lumen diameter reduction. Eur J Intern Med 2016;28:74-9.

26. Gariepy J, Denarie N, Chironi G, et al. Gender difference in the influence of smoking on arterial wall thickness. Atherosclerosis 2000;153:139-45.

27. Poredos P, Kek A, Verhovec R. Morphological and functional changes of the arterial wall in subjects at risk of atherosclerosis and in patients with peripheral arterial occlusive disease. Vasa 1997;26:271-6. 
28. Yamasaki Y, Kodama M, Nishizawa H, et al. Carotid intima-media thickness in Japanese type 2 diabetic subjects: predictors of progression and relationship with incident coronary heart disease. Diabetes Care 2000;23:1310-5.

29. Zanchetti A, Crepaldi G, Bond MG, et al. Systolic and pulse blood pressures (but not diastolic blood pressure and serum cholesterol) are associated with alterations in carotid intima-media thickness in the moderately hypercholesterolaemic hypertensive patients of the Plaque Hypertension Lipid Lowering Italian Study. PHYLLIS study group. J Hypertens 2001;19:79-88.

30. Magnussen CG. Carotid artery intima-media thickness and hypertensive heart disease: a short review. Clin Hypertens 2017;23:7.

31. Zizek B, Poredos P. Dependence of morphological changes of the carotid arteries on essential hypertension and accompanying risk factors. Int Angiol 2002;21:70-7.

32. Bots ML, Sutton-Tyrrell K. Lessons from the past and promises for the future for carotid intima-media thickness. J Am Coll Cardiol 2012;60:1599-604.

33. Salonen JT, Salonen R. Ultrasound B-mode imaging in observational studies of atherosclerotic progression. Circulation 1993;87:II56-65.

34. Burke GL, Evans GW, Riley WA, et al. Arterial wall thickness is associated with prevalent cardiovascular disease in middle-aged adults. The Atherosclerosis Risk in Communities (ARIC) Study. Stroke 1995;26:386-91.

35. Bots ML, Hofman A, Grobbee DE. Common carotid intima-media thickness and lower extremity arterial atherosclerosis. The Rotterdam Study. Arterioscler Thromb 1994;14:1885-91.

36. Schreiner PJ, Heiss G, Tyroler HA, et al. Race and gender differences in the association of $\mathrm{Lp}(\mathrm{a})$ with carotid artery wall thickness. The Atherosclerosis Risk in Communities (ARIC) Study. Arterioscler Thromb Vasc Biol 1996;16:471-8.

37. Hodis HN, Mack WJ, LaBree L, et al. The role of carotid arterial intima-media thickness in predicting clinical coronary events. Ann Intern Med 1998;128:262-9.

38. Liu D, Du C, Shao W, et al. Diagnostic Role of Carotid Intima-Media Thickness for Coronary Artery Disease: A Meta-Analysis. Biomed Res Int 2020;2020:9879463.

39. Bots ML, Baldassarre D, Simon A, et al. Carotid intimamedia thickness and coronary atherosclerosis: weak or strong relations? Eur Heart J 2007;28:398-406.

40. Salonen JT, Salonen R. Ultrasonographically assessed carotid morphology and the risk of coronary heart disease. Arterioscler Thromb 1991;11:1245-9.
41. Chambless LE, Heiss G, Folsom AR, et al. Association of coronary heart disease incidence with carotid arterial wall thickness and major risk factors: the Atherosclerosis Risk in Communities (ARIC) Study, 1987-1993. Am J Epidemiol 1997;146:483-94.

42. O'Leary DH, Polak JF, Kronmal RA, et al. Distribution and correlates of sonographically detected carotid artery disease in the Cardiovascular Health Study. The CHS Collaborative Research Group. Stroke 1992;23:1752-60.

43. Lorenz MW, Schaefer C, Steinmetz H, et al. Is carotid intima media thickness useful for individual prediction of cardiovascular risk? Ten-year results from the Carotid Atherosclerosis Progression Study (CAPS). Eur Heart J 2010;31:2041-8.

44. Polak JF, Pencina MJ, Pencina KM, et al. Carotid-wall intima-media thickness and cardiovascular events. N Engl J Med 2011;365:213-21.

45. Cardoso CRL, Salles GC, Leite NC, et al. Prognostic impact of carotid intima-media thickness and carotid plaques on the development of micro- and macrovascular complications in individuals with type 2 diabetes: the Rio de Janeiro type 2 diabetes cohort study. Cardiovasc Diabetol 2019;18:2.

46. Lorenz MW, Polak JF, Kavousi M, et al. Carotid intimamedia thickness progression to predict cardiovascular events in the general population (the PROG-IMT collaborative project): a meta-analysis of individual participant data. Lancet 2012;379:2053-62.

47. del Sol AI, Moons KG, Hollander M, et al. Is carotid intima-media thickness useful in cardiovascular disease risk assessment? The Rotterdam Study. Stroke 2001;32:1532-8.

48. Touboul PJ, Labreuche J, Vicaut E, et al. Carotid intimamedia thickness, plaques, and Framingham risk score as independent determinants of stroke risk. Stroke 2005;36:1741-5.

49. Yeboah J, McClelland RL, Polonsky TS, et al. Comparison of novel risk markers for improvement in cardiovascular risk assessment in intermediate-risk individuals. JAMA 2012;308:788-95.

50. Simon A, Megnien JL, Chironi G. The value of carotid intima-media thickness for predicting cardiovascular risk. Arterioscler Thromb Vasc Biol 2010;30:182-5.

51. Summary of the second report of the National Cholesterol Education Program (NCEP) Expert Panel on Detection, Evaluation, and Treatment of High Blood Cholesterol in Adults (Adult Treatment Panel II) JAMA 1993;269:3015-23. 
52. de la Sierra A, Zamorano JL, Ruilope LM. Application of hypertension guidelines in clinical practice: implementation of the 2007 ESH/ESC European practice Guidelines in Spain. J Hypertens Suppl 2009;27:S27-32.

53. Den Ruijter HM, Peters SA, Anderson TJ, et al. Common carotid intima-media thickness measurements in cardiovascular risk prediction: a meta-analysis. JAMA 2012;308:796-803.

54. Stein JH, Tattersall MC. Carotid intima-media thickness and cardiovascular disease risk prediction. J Am Coll Cardiol 2014;63:2301-2.

55. Goff DC Jr, Lloyd-Jones DM, Bennett G, et al. 2013 ACC/AHA guideline on the assessment of cardiovascular risk: a report of the American College of Cardiology/ American Heart Association Task Force on Practice Guidelines. J Am Coll Cardiol 2014;63:2935-59.

56. Saba L, Jamthikar A, Gupta D, et al. Global perspective on carotid intima-media thickness and plaque: should the current measurement guidelines be revisited? Int Angiol 2019;38:451-65.

57. Naqvi TZ, Lee MS. Carotid intima-media thickness and plaque in cardiovascular risk assessment. JACC Cardiovasc Imaging 2014;7:1025-38.

58. Polak JF, Szklo M, O'Leary DH. Carotid Intima-Media Thickness Score, Positive Coronary Artery Calcium Score, and Incident Coronary Heart Disease: The Multi-Ethnic Study of Atherosclerosis. J Am Heart Assoc 2017;6:004612.

59. Stein JH, Korcarz CE, Hurst RT, et al. Use of carotid ultrasound to identify subclinical vascular disease and evaluate cardiovascular disease risk: a consensus statement from the American Society of Echocardiography Carotid Intima-Media Thickness Task Force. Endorsed by the Society for Vascular Medicine. J Am Soc Echocardiogr 2008;21:93-111; quiz 189-90.

60. Li M, Li L, Wu W, et al. Biomechanical characteristics of isolated carotid atherosclerotic plaques assessed by ultrasonography. Int Angiol 2019;38:443-50.

61. Poredos P, Gregoric ID, Jezovnik MK. Inflammation of carotid plaques and risk of cerebrovascular events. Ann Transl Med 2020;8:1281.

62. de Ruijter W, Westendorp RG, Assendelft WJ, et al. Use of Framingham risk score and new biomarkers to predict cardiovascular mortality in older people: population based observational cohort study. BMJ 2009;338:a3083.

63. Gepner AD, Young R, Delaney JA, et al. Comparison of coronary artery calcium presence, carotid plaque presence, and carotid intima-media thickness for cardiovascular disease prediction in the Multi-Ethnic Study of
Atherosclerosis. Circ Cardiovasc Imaging 2015;8:e002262.

64. Inaba Y, Chen JA, Bergmann SR. Carotid plaque, compared with carotid intima-media thickness, more accurately predicts coronary artery disease events: a metaanalysis. Atherosclerosis 2012;220:128-33.

65. Bea AM, Civeira F, Jarauta E, et al. Association Between the Presence of Carotid Artery Plaque and Cardiovascular Events in Patients With Genetic Hypercholesterolemia. Rev Esp Cardiol (Engl Ed) 2017;70:551-8.

66. Shah PK. Can carotid plaque predict coronary plaque? JACC Cardiovasc Imaging 2013;6:1168-71.

67. Triposkiadis F, Sitafidis G, Kostoulas J, et al. Carotid plaque composition in stable and unstable coronary artery disease. Am Heart J 2005;150:782-9.

68. Hellings WE, Peeters W, Moll FL, et al. Composition of carotid atherosclerotic plaque is associated with cardiovascular outcome: a prognostic study. Circulation 2010;121:1941-50.

69. Mitchell C, Korcarz CE, Gepner AD, et al. Ultrasound carotid plaque features, cardiovascular disease risk factors and events: The Multi-Ethnic Study of Atherosclerosis. Atherosclerosis 2018;276:195-202.

70. Zavodni AE, Wasserman BA, McClelland RL, et al. Carotid artery plaque morphology and composition in relation to incident cardiovascular events: the MultiEthnic Study of Atherosclerosis (MESA). Radiology 2014;271:381-9.

71. Paraskevas KI, Sillesen HH, Rundek T, et al. Carotid Intima-Media Thickness Versus Carotid Plaque Burden for Predicting Cardiovascular Risk. Angiology 2020;71:108-11.

72. Kolkenbeck-Ruh A, Woodiwiss AJ, Monareng T, et al. Complementary Impact of Carotid Intima-Media Thickness With Plaque in Associations With Noncardiac Arterial Vascular Events. Angiology 2020;71:122-30.

73. Spence JD. Measurement of intima-media thickness vs. carotid plaque: uses in patient care, genetic research and evaluation of new therapies. Int J Stroke 2006;1:216-21.

74. Sillesen H, Sartori S, Sandholt B, et al. Carotid plaque thickness and carotid plaque burden predict future cardiovascular events in asymptomatic adult Americans. Eur Heart J Cardiovasc Imaging 2018;19:1042-50.

75. Johnsen SH, Mathiesen EB, Joakimsen O, et al. Carotid atherosclerosis is a stronger predictor of myocardial infarction in women than in men: a 6-year followup study of 6226 persons: the Tromsø Study. Stroke 2007;38:2873-80.

76. Sillesen H, Muntendam P, Adourian A, et al. Carotid 
plaque burden as a measure of subclinical atherosclerosis: comparison with other tests for subclinical arterial disease in the High Risk Plaque BioImage study. JACC Cardiovasc Imaging 2012;5:681-9.

77. Ainsworth CD, Blake CC, Tamayo A, et al. 3D ultrasound measurement of change in carotid plaque volume: a tool for rapid evaluation of new therapies. Stroke 2005;36:1904-9.

78. O'Leary DH, Polak JF, Kronmal RA, et al. Carotid-artery intima and media thickness as a risk factor for myocardial infarction and stroke in older adults. Cardiovascular

Cite this article as: Poredos P, Jezovnik MK. Preclinical carotid atherosclerosis as an indicator of polyvascular disease: a narrative review. Ann Transl Med 2021;9(14):1204. doi: 10.21037/atm-20-5570
Health Study Collaborative Research Group. N Engl J Med 1999;340:14-22.

79. Blankenhorn DH, Johnson RL, Nessim SA, et al. The Cholesterol Lowering Atherosclerosis Study (CLAS): design, methods, and baseline results. Control Clin Trials 1987;8:356-87.

80. Bots ML, Hoes AW, Koudstaal PJ, et al. Common carotid intima-media thickness and risk of stroke and myocardial infarction: the Rotterdam Study. Circulation 1997;96:1432-7. 